Published in: Mater. Sci. Eng. A, 2000, vol. 289, pp. 130-142

\title{
Embrittlement of Al-Li-Cu-Mg alloys at slightly elevated temperatures: microstructural mechanisms of hardening
}

\author{
M.J. Starink ${ }^{*}$, A.J. Hobson, I. Sinclair and P.J. Gregson \\ Materials Research Group, School of Engineering Sciences, University of Southampton, \\ Southampton S017 1BJ, UK
}

Keywords: 8090 Al alloy, Toughness, Al-Li-Cu-Mg, Guinier-Preston zone, Solvus of $\delta$ ' phase

\begin{abstract}
When underaged, damage tolerant Al-Li based alloys are exposed to slightly elevated temperatures $\left(60\right.$ to $100^{\circ} \mathrm{C}$ ), their strength increases and toughness decreases. To study the first stages of this process, 8090 sheet in three underaged heat treatment conditions, including T3, T81 and a multistage temper, was exposed for $1000 \mathrm{~h}$ at $70^{\circ} \mathrm{C}$. Using a model for strengthening in combination with a quantitative analysis of differential scanning calorimetry data, it is shown that strengthening can be explained by an increase in the volume fraction of the $\delta^{\prime}$ phase and, to a lesser extent, to the formation of Guinier-Preston (GPB) zones. For the T3 temper, coarsening of $\delta^{\prime}$ precipitates is the main strengthening mechanism during exposure at $70^{\circ} \mathrm{C}$. The solvus of $\delta^{\prime}$ and GPB, which to a large extent defines this embrittlement, is discussed. Toughness reduction during exposure at slightly elevated temperatures can be minimised via a multi stage temper or via a reduction of the Li content of the alloy.
\end{abstract}

\section{Introduction}

Early work in the aircraft industry on Al-based alloys was focused on the development of high strength alloys, but more recently, the emphasis has changed to allow the development of alloys offering an improved combination of properties in particular damage tolerance, i.e. the ability to resist crack growth. For a given strength (design stress), damage tolerance may be improved through enhanced resistance to fatigue crack growth and/or improved fracture toughness.

* Corresponding author. Tel.: 00-44-2380-595094; Fax: 00-44-2380-593016;

E-mail address: M.J.Starink@soton.ac.uk 
For the 8090 (Al-Li-Cu-Mg-Zr) alloy a good combination of specific strength and toughness can be achieved by underageing, e.g. the T81 treatment, which consists of solution treatment, stretch, natural ageing (= ageing at ambient temperature) and artificial ageing $\left(24 \mathrm{~h}\right.$ at $\left.150^{\circ} \mathrm{C}\right)[1,2]$. Unfortunately, Al-Li based alloys in this damage tolerant condition strengthen and reduce in toughness when exposed to slightly elevated temperatures around 60 to $100^{\circ} \mathrm{C}[3,4]$. Clearly, this poses a serious problem for many of the potential applications for aluminium-lithium alloys especially in terms of safe-life calculations. For example, aircraft skins in the vicinity of jet and auxiliary power unit exhausts, aircraft used at high mach numbers, and aircraft left standing in strong sunlight could all be expected to be exposed to temperatures above $60^{\circ} \mathrm{C}$ for long periods.

There have been various suggestions for the causes of the decrease in toughness of Al-Li based alloys when exposed to slightly elevated temperatures. For 8090 alloys these include the segregation of lithium atoms to the grain boundaries [5], formation of $\mathrm{Cu}$ and $\mathrm{Mg}$ containing Guinier-Preston zones (GPB) [6], the precipitation of fine $\mathrm{L}_{2}$ ordered $\delta^{\prime}$ phase $[1,6]$ and the coarsening of $\delta^{\prime}$ [4]. For $\mathrm{Cu}$ free Al-Li based alloys, mostly the precipitation of fine $\delta^{\prime}$ has been identified as the mechanism for reduction of toughness and a transition between the two processes of nucleation of fine $\delta^{\prime}$ and coarsening of pre-existing $\delta^{\prime}$ depending upon exposure temperature and cooling rate to the final exposure temperature has been reported $[7,8]$.

This paper sets out to establish an improved understanding of the microstructural changes which are responsible for the thermal instability of the aluminium alloy 8090 in damage tolerant tempers as well as to evaluate recently developed multi-step ageing treatments [4] which reduce the property instabilities. We will focus especially on the first stages of embrittlement, up to $1000 \mathrm{~h}$ at $70^{\circ} \mathrm{C}$.

\section{Experimental}

Alloy sheet of 8090 specification was supplied by Alcan International (composition given in Table 1). The post homogenisation processing included hot rolling to $3.5 \mathrm{~mm}$ thickness, annealing and finally cold rolling to $2.1 \mathrm{~mm}$ thickness. The sheet was solution treated at $530^{\circ} \mathrm{C}$ for 30 minutes and cold water quenched prior to thermo-mechanical treatments:

T3 - 2\% stretch plus natural ageing (for more than one year) as described above.

$\mathrm{T} 81$ - T3 plus additional ageing for $24 \mathrm{~h}$ at $150^{\circ} \mathrm{C}$, a commonly used standard in industry for the production of damage tolerant alloys. 
Retrogressive step wise (RSW) - a heat treatment developed by Avro International Aerospace Ltd./British Aerospace plc (see e.g. [9]) consisting of a series of four cumulative heat treatments applied to material in the $\mathrm{T} 3$ condition: $1 \mathrm{~h}$ at $150^{\circ} \mathrm{C}, 8 \mathrm{~h}$ at $120^{\circ} \mathrm{C}, 24 \mathrm{~h}$ at $105^{\circ} \mathrm{C}$ and $8 \mathrm{~h}$ at $95^{\circ} \mathrm{C}$, with air cooling to ambient between each step.

Thermal Exposure at $70^{\circ} \mathrm{C}\left(\mathrm{X} 70^{\circ} \mathrm{C}\right)$ - this treatment has been carried out as an addition to the previous three conditions, and is intended to be representative of the maximum temperature the alloy will reach in service.

In addition to the work on the 8090 sheet limited experiments were performed on 8090 and 1441 plate. Compositions are listed in Table 1 and all plate material was received from the suppliers in a standard damage tolerant $\mathrm{T} 8$ condition which included a final ageing treatment of $24 \mathrm{~h}$ at $150^{\circ} \mathrm{C}$.

Duplicate tensile tests were carried out for each heat treatment condition, both in the rolling direction ( $\mathrm{L}$ direction), and transverse to the rolling direction ( $\mathrm{T}$ direction). Macro hardness tests ("10 kg" load) were carried out on all heat treatment conditions and each result is the average of three tests.

Sheet specimens of $57.2 \times 36.5 \mathrm{~mm}$ ( T x L) with a centre notch in the L direction and loading holes at $1 / 4$ and $3 / 4$ of the dimension in the $T$ direction were machined and tear tests were carried out with the tensile axis in the T direction (this is a so-called Kahn tear test, for further details see Ref. [10]). After allowing for the plastic deformation at the loading holes (as measured using a specimen without notch), fracture energy was calculated in terms of propagation energy (W) and initiation energy. Generally, the total propagation energy is used to represent the toughness of the material as it has been found that this correlates with the $\mathrm{K}_{1 \mathrm{C}}$ value for a given material. For plate material standard Charpy impact toughness tests were performed on T-L samples. Toughness results are typically reproducible within about $3 \%$.

Scanning electron microscopy (Jeol JSM 6400 and Jeol T300) was used to study fracture surfaces from the tensile and toughness tests on the sheet material. Foils for transmission electron microscopy (TEM) were prepared using standard techniques (see e.g. Ref. 11) and they were investigated using a Jeol 2000FX microscope. $\delta$ ' phase particles were imaged in dark field conditions (see e.g. $[4,11,13])$.

To study matrix precipitation in the alloy differential scanning calorimetry (DSC) experiments were performed employing a heating rate of $10 \mathrm{~K} / \mathrm{min}$ (for further details and correction procedures see $[11,12])$. The presented DSC curves represent heat flows due to reactions only. The procedure 
used for preparation of the DSC samples influences the resulting DSC curve obtained [12]. For the present work, two types of preparation techniques of T3 8090 were evaluated. In the first one a disk shaped DSC sample was punched out of a ground sheet and in the second one a disk shaped DSC sample was electrochemically removed from a ground sheet. The two resulting DSC curves were very similar, and hence the more convenient preparation technique of punching was selected for the present study.

Table 1 Compositions of alloys (in wt \%).

\begin{tabular}{lcccc}
\hline Alloy & $\mathrm{Li}$ & $\mathrm{Cu}$ & $\mathrm{Mg}$ & $\mathrm{Zr}$ \\
\hline 8090 sheet & 2.33 & 1.22 & 0.71 & 0.06 \\
8090 plate & 2.30 & 0.99 & 0.64 & 0.07 \\
1441 plate & 2.00 & 1.80 & 0.85 & 0.12 \\
\hline
\end{tabular}

\section{Results}

\subsection{Mechanical properties 8090 sheet and plate.}

Mechanical test data for T3, RSW and T81 8090 sheet prior to exposure are presented in Table 2. As expected, the naturally aged T3 material has the lowest strength and the artificially aged T81 condition the highest strength. As a result of the texture of the rolled sheets, the orientation of the tests affects the tensile properties, with the $\mathrm{L}$ direction specimens having the higher $0.2 \%$ proof stress by 15 to $30 \mathrm{MPa}$. In terms of the ultimate tensile strength (UTS) of aged 8090 materials, this difference between $\mathrm{L}$ and $\mathrm{T}$ directions is much reduced (T81) or even reversed (RSW). The propagation energies for the unexposed heat treatment conditions show that T3 provides the greatest toughness whilst those for RSW and T81 are very similar despite differences in yield stress of $30 \mathrm{MPa}$.

Mechanical test data for the exposed $\left(1000 \mathrm{~h}\right.$ at $\left.70^{\circ} \mathrm{C}\right) \mathrm{T} 3$, T81 and RSW samples are presented in Table 3. It can be seen that the T3 and T81 8090 samples are unstable with respect to strength, elongation and toughness, whilst the RSW 8090 sample is stable with respect to toughness, but unstable for strength and elongation. Data on longer term exposure at $70^{\circ} \mathrm{C}$ (up to $4000 \mathrm{~h}$ ) has revealed [4] that also RSW samples exhibit a reduction in toughness. A plot of the yield strength 
vs. the toughness is presented in Fig. 1. In general the largest changes caused by exposure are seen for the T3 condition, with the proof stress in all orientations increasing by $\sim 50 \mathrm{MPa}$. Also in terms of the propagation energy the T3 condition shows the greatest changes.

Table 2 Mechanical test data for unexposed 8090 sheet. $\sigma_{0.2}$ is the $0.2 \%$ offset yield strength, $\sigma_{\text {UTS }}$ is the ultimate tensile strength, $\mathrm{n}$ is the work hardening coefficient, $\mathrm{W}$ is the propagation energy, HV is the Vickers hardness.

\begin{tabular}{|c|c|c|c|c|c|c|c|}
\hline Condition & Orientation & $\begin{array}{c}\sigma_{0.2} \\
(\mathrm{MPa})\end{array}$ & $\begin{array}{c}\sigma_{\text {UTS }} \\
(\mathrm{MPa})\end{array}$ & $\begin{array}{c}\text { Elongation } \\
(\%)\end{array}$ & $\mathrm{n}$ & $\begin{array}{c}\mathrm{W} \\
\text { (KN.mm) }\end{array}$ & $\mathrm{HV}$ \\
\hline $\mathrm{T} 3$ & $\mathrm{~T}$ & 169 & 322 & 20.3 & 0.15 & 11.6 & 89 \\
\hline $\mathrm{T} 3$ & $\mathrm{~L}$ & 201 & 347 & 20.2 & 0.12 & & \\
\hline $\mathrm{T} 81$ & $\mathrm{~T}$ & 284 & 432 & 13.2 & 0.12 & 5.9 & 126 \\
\hline $\mathrm{T} 81$ & L & 318 & 432 & 12.0 & 0.08 & & \\
\hline RSW & $\mathrm{T}$ & 252 & 398 & 16.5 & 0.12 & 6.2 & 113 \\
\hline RSW & $\mathrm{L}$ & 267 & 390 & 14.4 & 0.09 & & \\
\hline
\end{tabular}

Table 3 Mechanical test data for exposed 8090 sheet. Exposure (X) consists of $1000 \mathrm{~h}$ at $70^{\circ} \mathrm{C}$.

\begin{tabular}{lccccccc}
\hline Condition & Orientation & $\begin{array}{c}\sigma_{0.2} \\
(\mathrm{MPa})\end{array}$ & $\begin{array}{c}\sigma_{\mathrm{UTS}} \\
(\mathrm{MPa})\end{array}$ & $\begin{array}{c}\text { Elongation } \\
(\%)\end{array}$ & $\mathrm{n}$ & $\mathrm{W}$ & $\mathrm{HV}$ \\
$\mathrm{T} 3+\mathrm{X}$ & $\mathrm{T}$ & 222 & 371 & 19.1 & 0.14 & 7.8 & 106 \\
$\mathrm{~T} 3+\mathrm{X}$ & $\mathrm{L}$ & 245 & 367 & 22.2 & 0.08 & & \\
$\mathrm{~T} 81+\mathrm{X}$ & $\mathrm{T}$ & 309 & 454 & 11.4 & 0.12 & 4.3 & 128 \\
$\mathrm{~T} 81+\mathrm{X}$ & $\mathrm{L}$ & 336 & 442 & 10.9 & 0.08 & & \\
$\mathrm{RSW}+\mathrm{X}$ & $\mathrm{T}$ & 269 & 420 & 13.2 & 0.12 & 6.2 & 119 \\
$\mathrm{RSW}+\mathrm{X}$ & $\mathrm{L}$ & 299 & 410 & 13.7 & 0.08 & & \\
\hline
\end{tabular}

Table 3 shows that changes in work hardening exponent after exposure are significant only for the T3 condition. After exposure the T3 condition still has the highest value of propagation energy and T81 still has the lowest value of propagation energy (Table 3 ). 
Yield Strength vs Propagation Energy

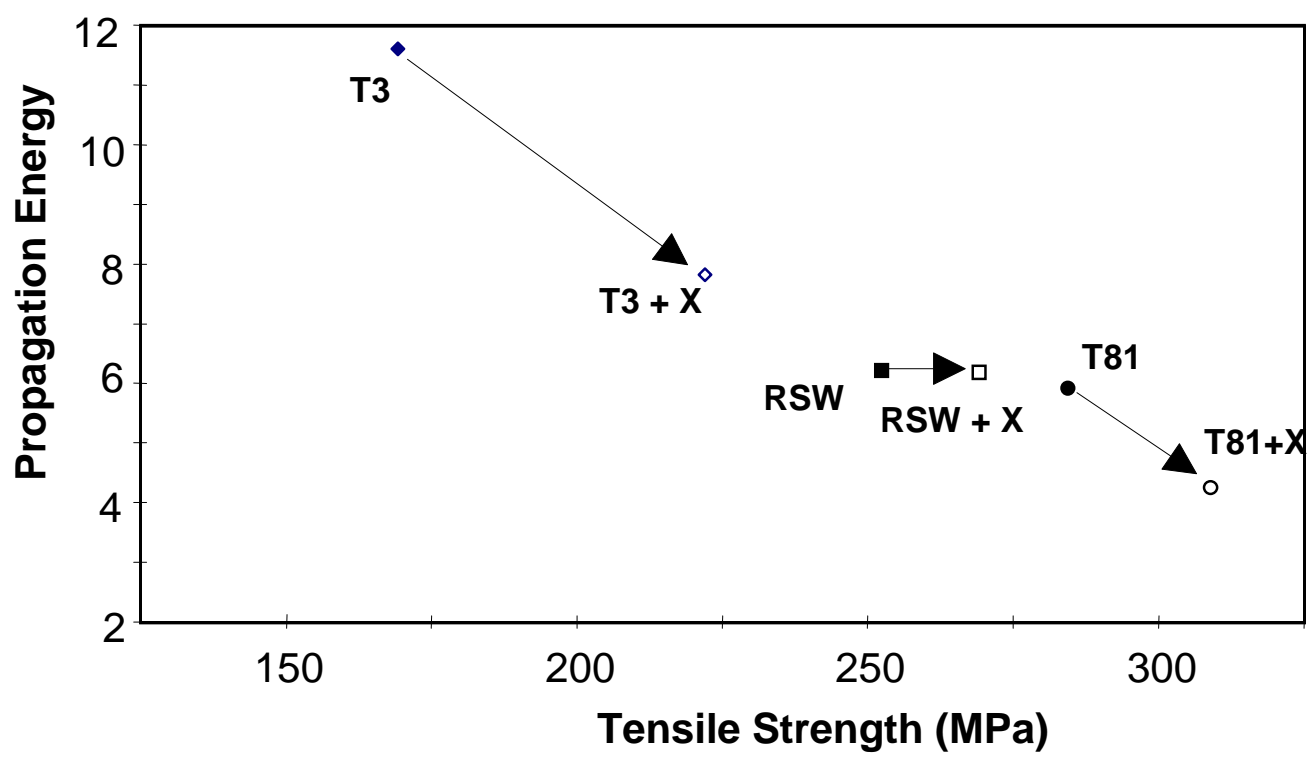

Fig. 1 Fracture Energy vs. Tensile Strength.

SEM fractography for the six heat treatment conditions investigated (Fig. 1) showed predominately transgranular shear failure, with limited amounts of intergranular failure. There was little observable difference between the unexposed and the exposed specimens of the same temper. The T81 material showed quite clear evidence of planar slip activity, with shear regions exhibiting a linear, relatively crystallographic appearance. The T3 samples exhibited a distinctly more diffuse ductile shear failure mode. The features observed on failed RSW specimens were intermediate between these two extremes. Limited intergranular failure was only appreciable in the T81 and $\mathrm{T} 81+\mathrm{X} 70^{\circ} \mathrm{C}$ samples.

\subsection{Analysis of the microstructures of $\mathbf{8 0 9 0}$ sheet}

TEM investigation showed the presence of $\delta^{\prime}$ phase particles in all heat treated conditions, whilst no $\mathrm{S}^{\prime}$ was observed. The average $\delta$ ' sizes for the unexposed samples is 2,6 and $9 \mathrm{~nm}$ for T3, RSW and T81 samples, respectively. Only for the T3 sample an increase in average $\delta$ ' size on exposure was detected: the size doubled from 2 to $4 \mathrm{~nm}$ for $\mathrm{T} 3+\mathrm{X}$.

EDX analysis in the SEM of dispersoids showed particles rich in $\mathrm{Al}, \mathrm{Fe}$ and $\mathrm{Cu}$, consistent with the $\mathrm{Al}_{7} \mathrm{Cu}_{2} \mathrm{Fe}$ phase which is generally present in $\mathrm{Cu}$ containing Al-based alloys of commercial purity. (Commercial Al-based alloys always contain some Fe and Si impurities.) These $\mathrm{Fe}$ containing dispersoids do not undergo transformations during heat treatment. 
Fig. 1 Fracture surfaces: a) T3, b) $\mathrm{T} 3+\mathrm{X} 70^{\circ} \mathrm{C}$ c) $\mathrm{RSW}$, d) $\mathrm{RSW}+\mathrm{X} 70^{\circ} \mathrm{C}$, e) $\left.\mathrm{T} 81, \mathrm{f}\right) \mathrm{T} 81+\mathrm{X} 70^{\circ} \mathrm{C}$

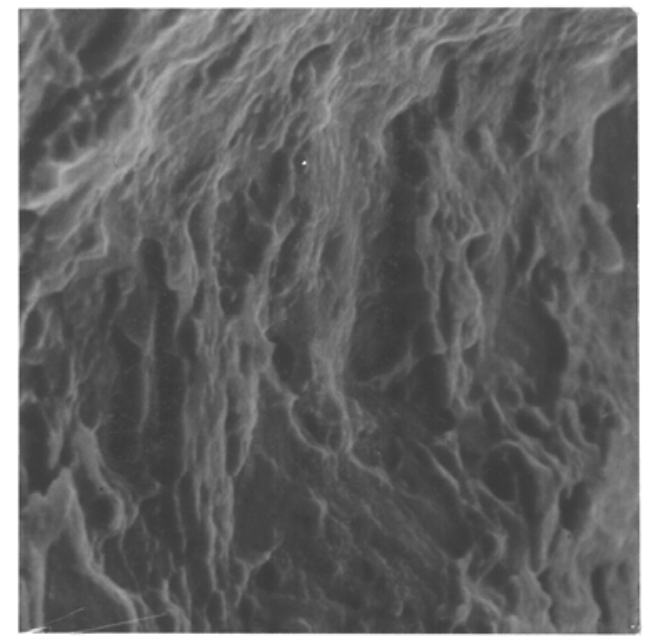

a

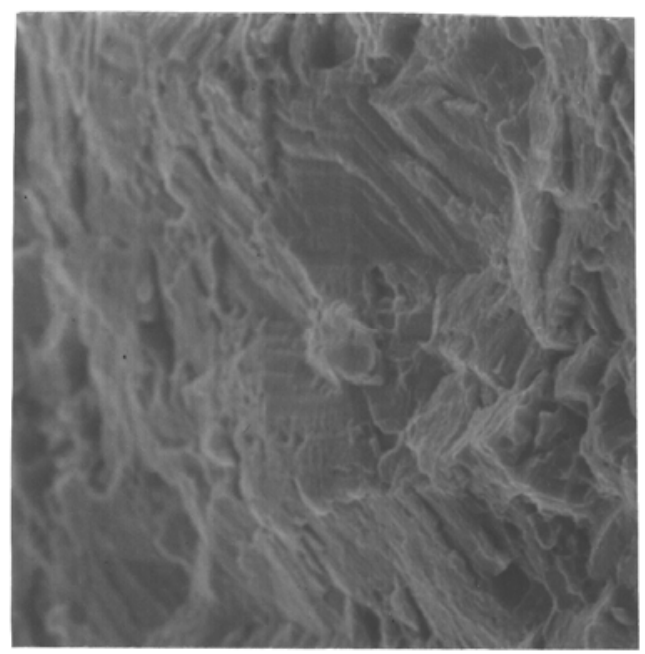

C

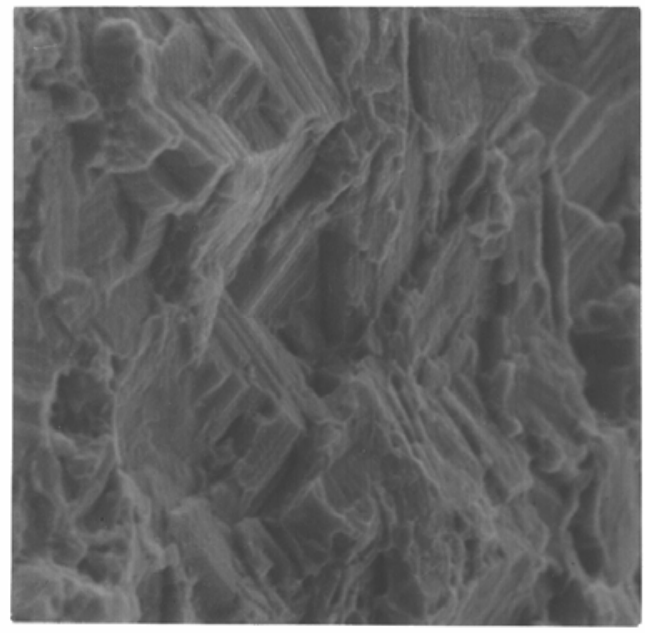

$\mid$

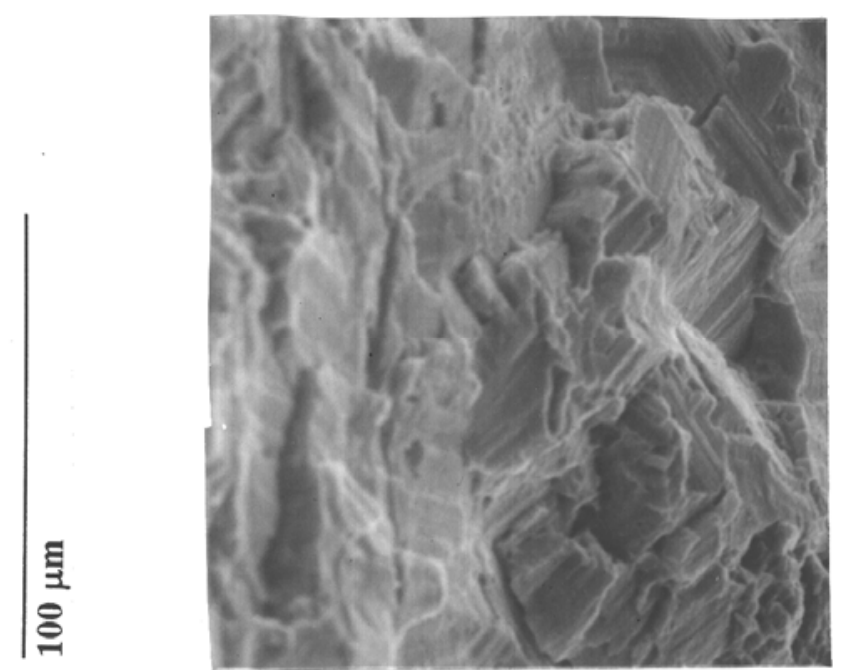

d

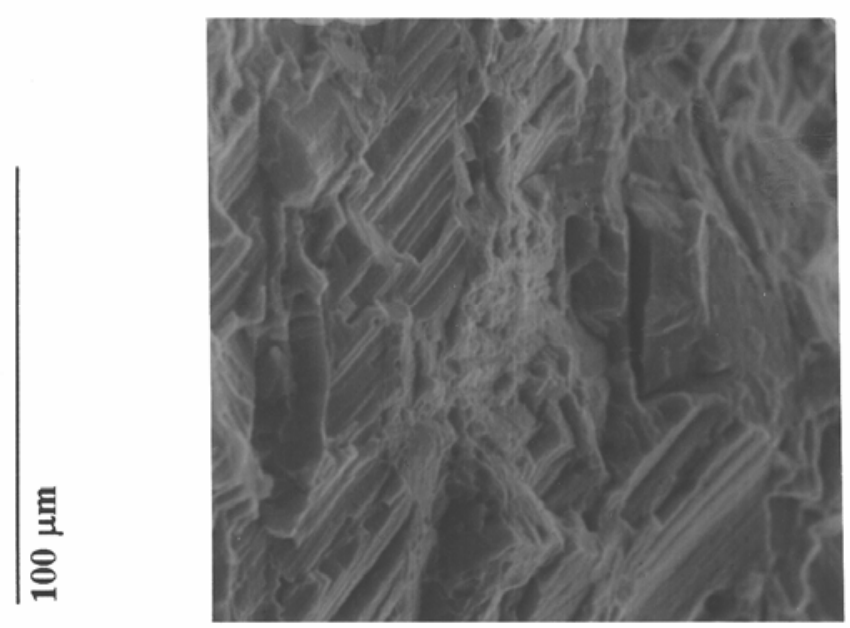

f

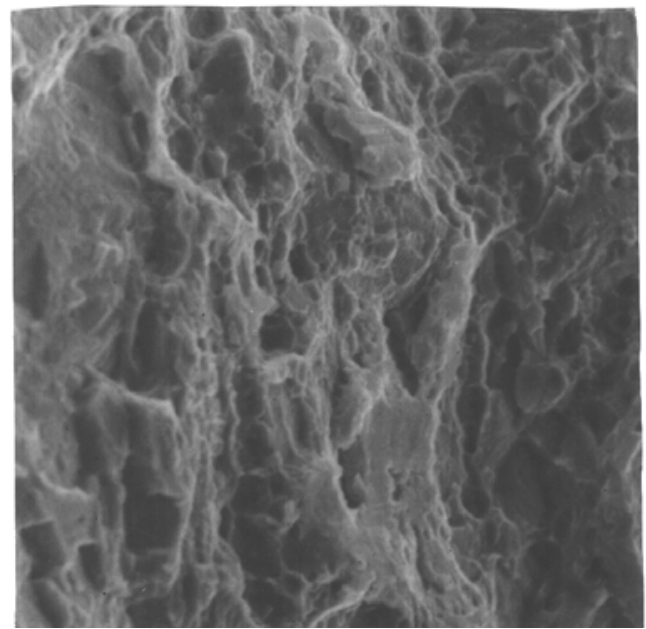

b 
To analyse the microstructural changes that occur during ageing and exposure, DSC experiments have been performed on 8090 sheet in various heat treated conditions. In general, the traces (Fig. 2 to 8) show up to six different effects which are labelled A to F (see Fig. 2). Previous work $[11,12,13]$ has attributed these effects to the following reactions:
A GPB zone formation.
B $\quad \delta^{\prime}$ precipitation.
C Dissolution of GPB zones and $\delta^{\prime}$.
D Precipitation of $\mathrm{S}^{\prime} / \mathrm{S}$.
E Dissolution of $\mathrm{S}^{\prime} / \mathrm{S}$.
F Oxidation reactions.

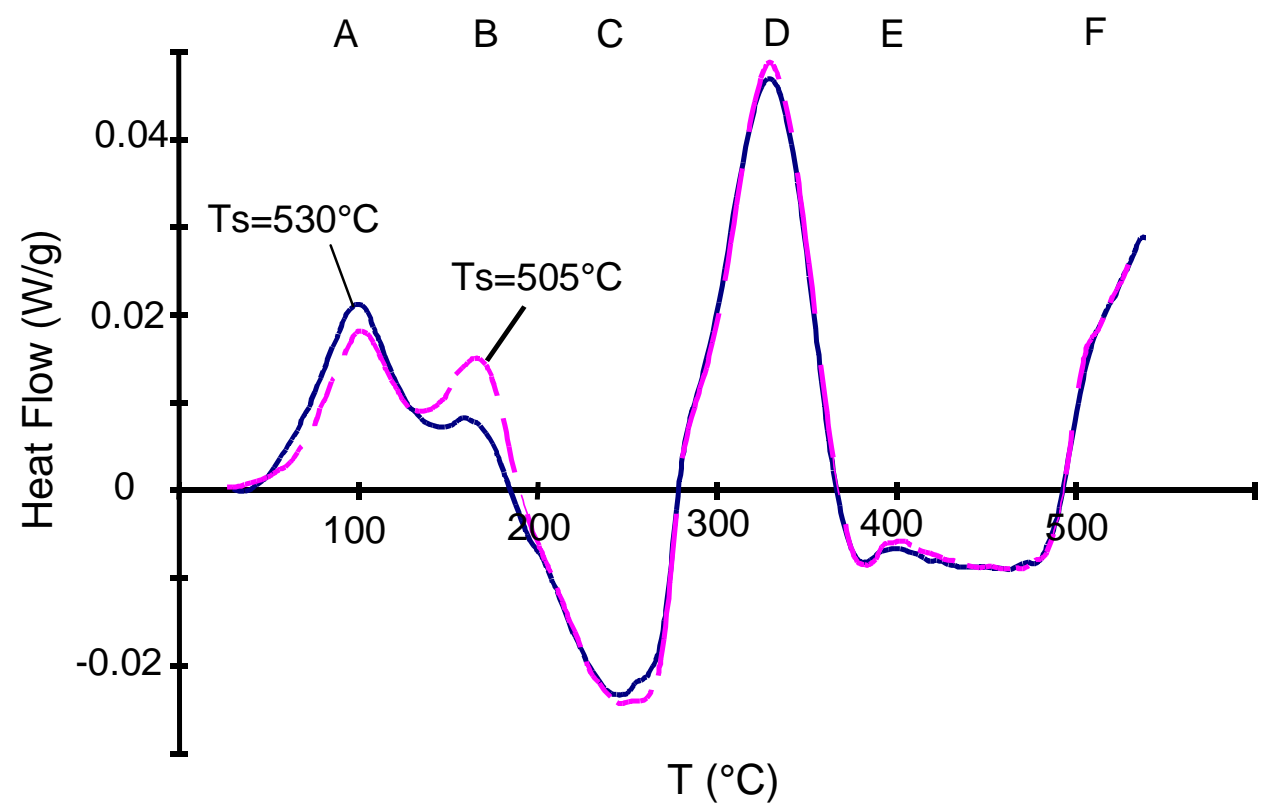

Fig. 2 DSC curves of 8090 sheet revealing the effect of solution treatment temperature.

DSC traces of freshly solution treated 8090 (Fig. 2) show the exothermic effects due to the formation of the GPB zones and $\delta^{\prime}$ phase. For the T3, RSW and T81 8090 samples significant GPB-zone and $\delta^{\prime}$ formation has occurred during ageing, and the DSC traces are endothermic up to the start of $\mathrm{S}^{\prime}$ formation at about $270^{\circ} \mathrm{C}$ (Figs. 4 to 8 ). The available evidence in the literature $[4,11,12,13,14,15,16,17,18]$, which includes HREM and SAXS data, leaves open several possibilities for the identification of the low temperature dissolution effects between 50 and $270^{\circ} \mathrm{C}$ as seen in these DSC curves. In samples artificially aged to full development of the $\delta^{\prime}$ and GPB zones (i.e. aged for several days at about $170^{\circ} \mathrm{C}$ ), the main low temperature dissolution event occurs between about 200 and $270^{\circ} \mathrm{C}$ [11]. This indicates that events occurring before $200^{\circ} \mathrm{C}$ in $\mathrm{T} 3$ and 
RSW samples are related to the following possible reactions i) dissolution of precursors of $\delta^{\prime}$ (endothermic), ii) dissolution of very fine $\delta^{\prime}$ precipitates that become unstable on increase of temperature (endothermic), iii) further ordering of $\mathrm{L}_{2}$ ordered domains (exothermic) iv) changes in the initially diffuse interface layer between $\delta^{\prime}$ and the matrix [14] leading to a sharper interface (exothermic) v) coarsening of $\delta^{\prime}$ (exothermic), vi) dissolution of GPB zones/clusters (endothermic). Clearly, the heat effects between 50 and $260^{\circ} \mathrm{C}$ in the DSC curves of the T3, RSW and T81 samples can be explained by various combinations of superpositions of the above 6 reactions. However, as precursors of $\delta^{\prime}$ have never been directly observed, and coarsening of $\delta^{\prime}$ (reaction v) is expected to cause only minor exothermic effects, it is suggested that all effects in the DSC curves between about 50 and $260^{\circ} \mathrm{C}$ are due to reactions ii, iii, iv and vi. Thus, in this interpretation, T3, RSW and T81 8090 samples contain only GPB zones and $\delta^{\prime}$ phase (with an initially diffuse $\delta^{\prime} /$ matrix interface layer). It will be shown below that this interpretation in consistent with the data on microstructure (DSC and TEM) and data on mechanical properties.

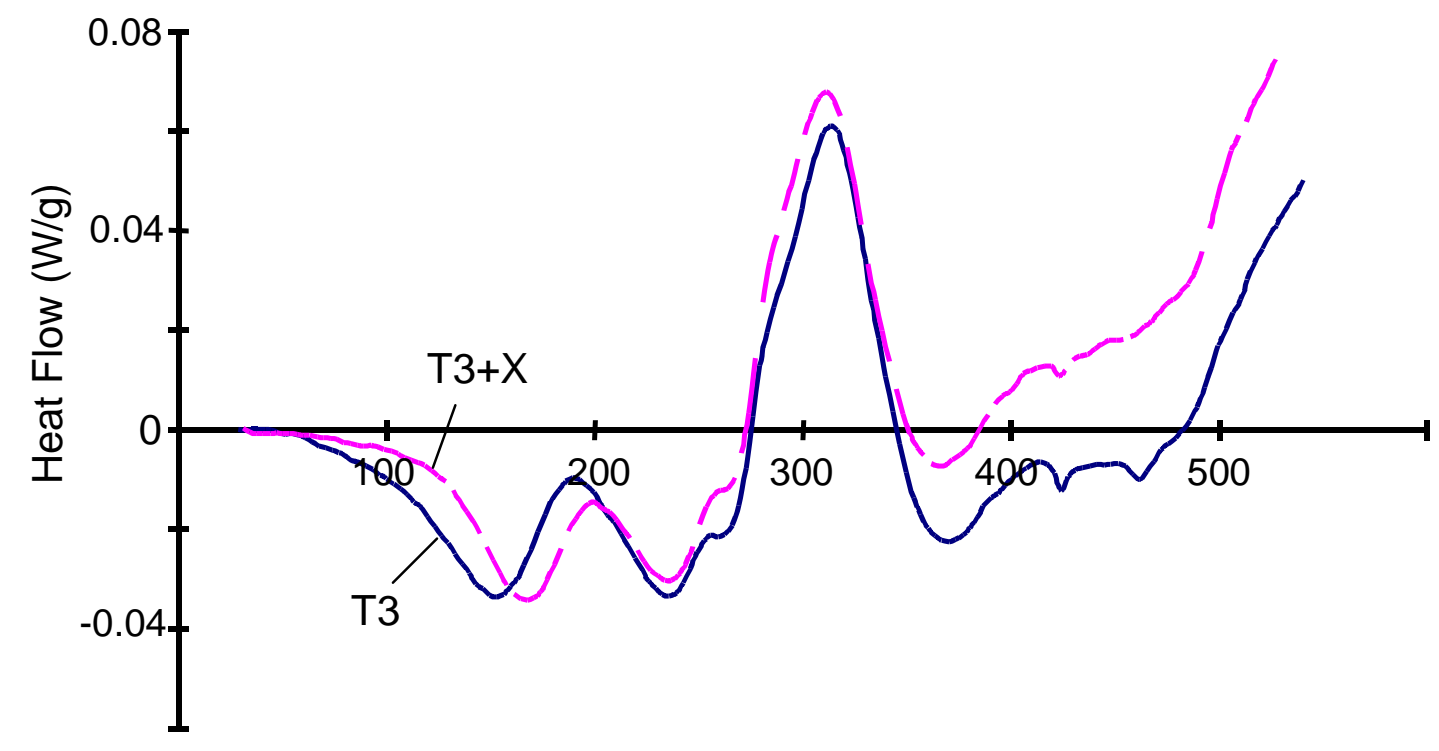

$\mathrm{T}\left({ }^{\circ} \mathrm{C}\right)$

Fig. 3 DSC curves of natural aged and natural aged $+\mathrm{X} 70^{\circ} \mathrm{C} 8090$ sheet.

The DSC curves for the T3 and the T3+X condition (Fig. 3) both show two dissolution effects below $270^{\circ} \mathrm{C}$. Both curves have a dissolution effect at a common temperature of approximately $230^{\circ} \mathrm{C}$, but with a small reduction in magnitude for the exposed T3 case. Notably, the lower temperature peak in the exposed T3 sample is shifted to a higher temperature. Fig. 4 demonstrates the effect of isothermal ageing at $150^{\circ} \mathrm{C}$. Curves for $1,4,8$ and 24 (T81) h show an apparent progression of the first dissolution peak towards the second as the ageing time is increased from $1 \mathrm{~h}$ 
to $24 \mathrm{~h}$. The magnitude of this first dissolution effect increases as it progresses toward the second fixed temperature effect.

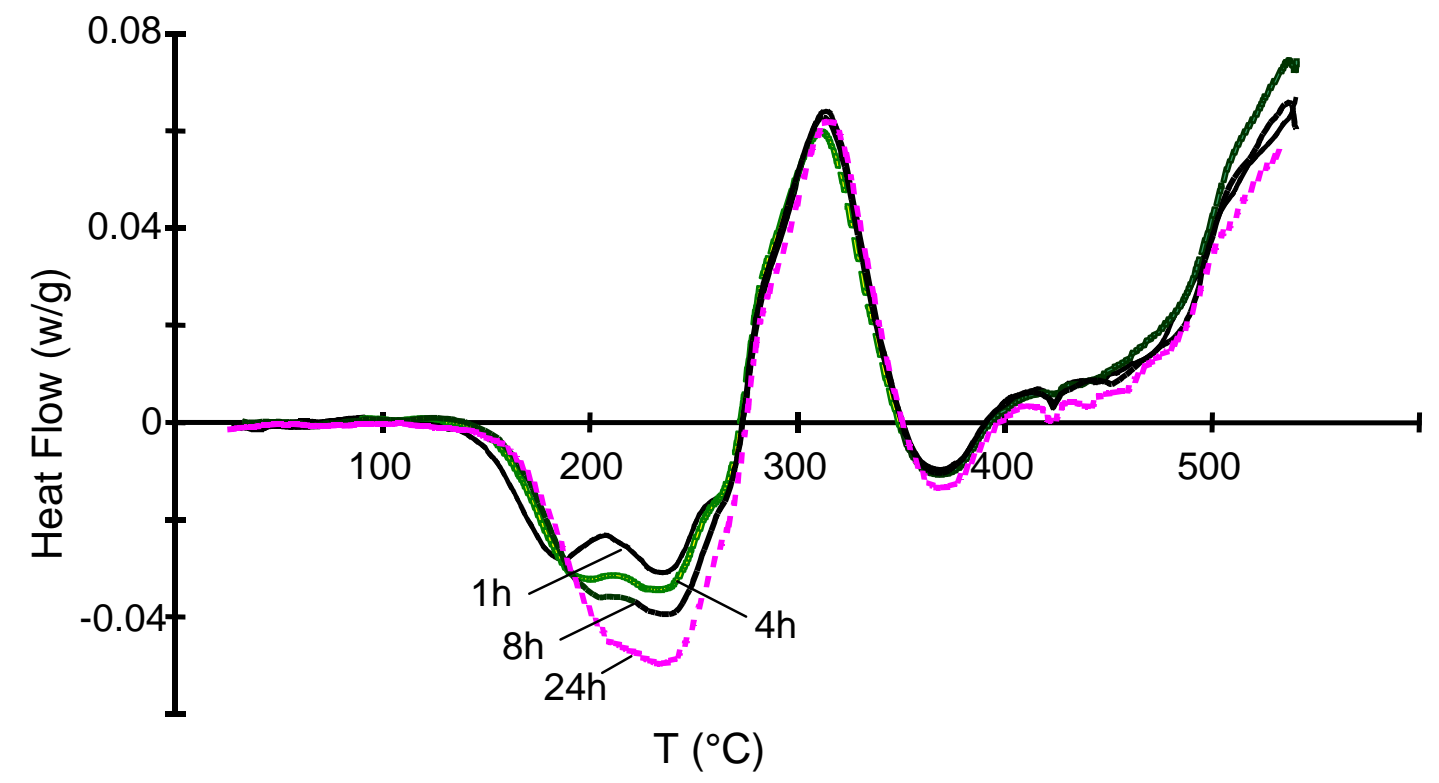

Fig. 4 DSC curves of 8090 sheet aged for $1,4,8$ and $24 \mathrm{~h}$ at $150^{\circ} \mathrm{C}$.

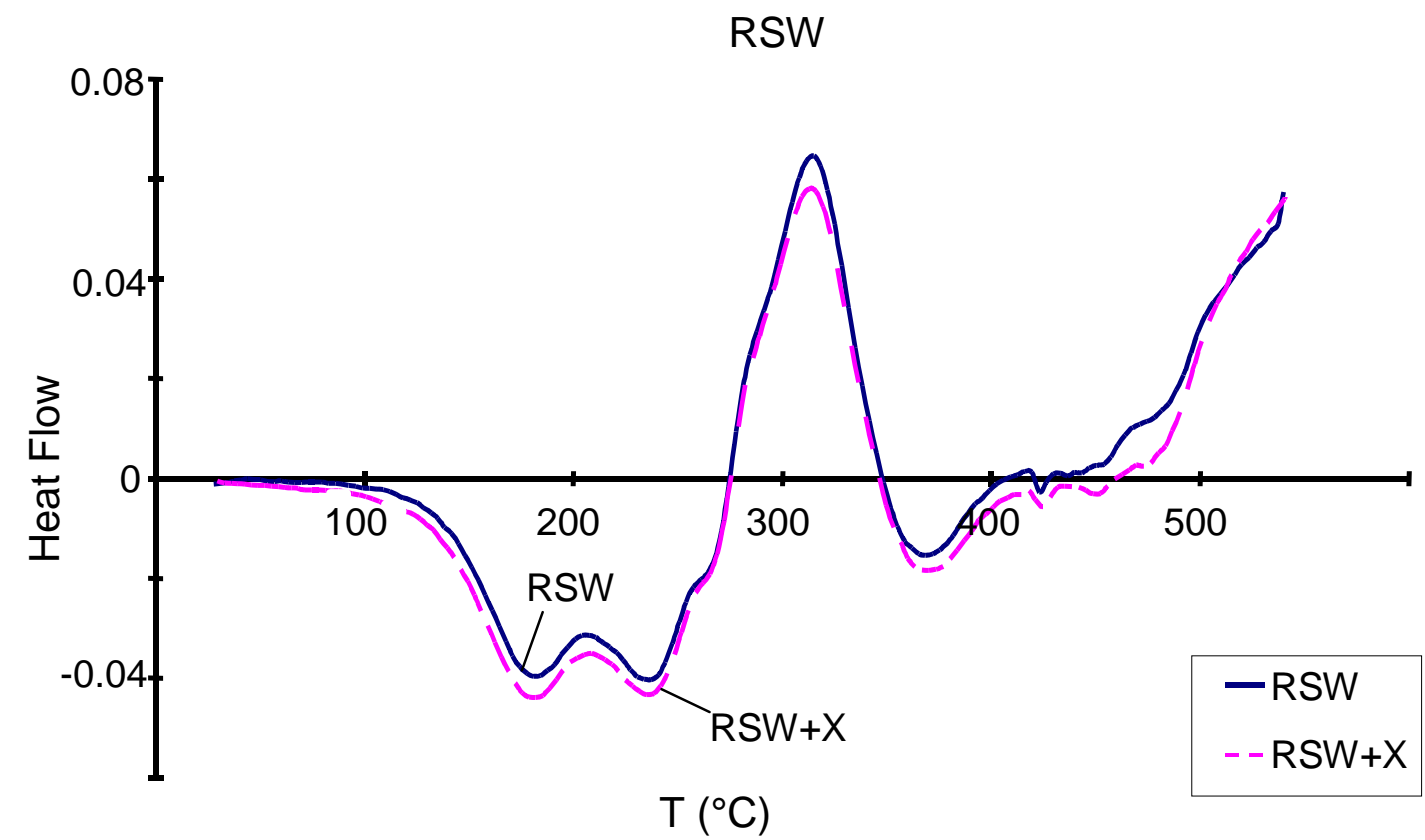

Fig. 5 DSC curves of RSW and RSW $+\mathrm{X} 70^{\circ} \mathrm{C} 8090$ sheet.

DSC traces for the RSW and the RSW + X condition (Fig. 5) show identical positions of the two low temperature dissolution effects and the effect of exposure is to increase the magnitude of the effects. The DSC curves in Fig. 6 demonstrate the cumulative effect of different steps in the RSW heat 
treatment. It can be seen again that the higher temperature dissolution effect occurs at a fixed temperature on each of the curves. After the addition of each ageing step the magnitude of both dissolution effects increases whilst the onset of the dissolution effect shifts to lower temperatures.

RSW (all steps)

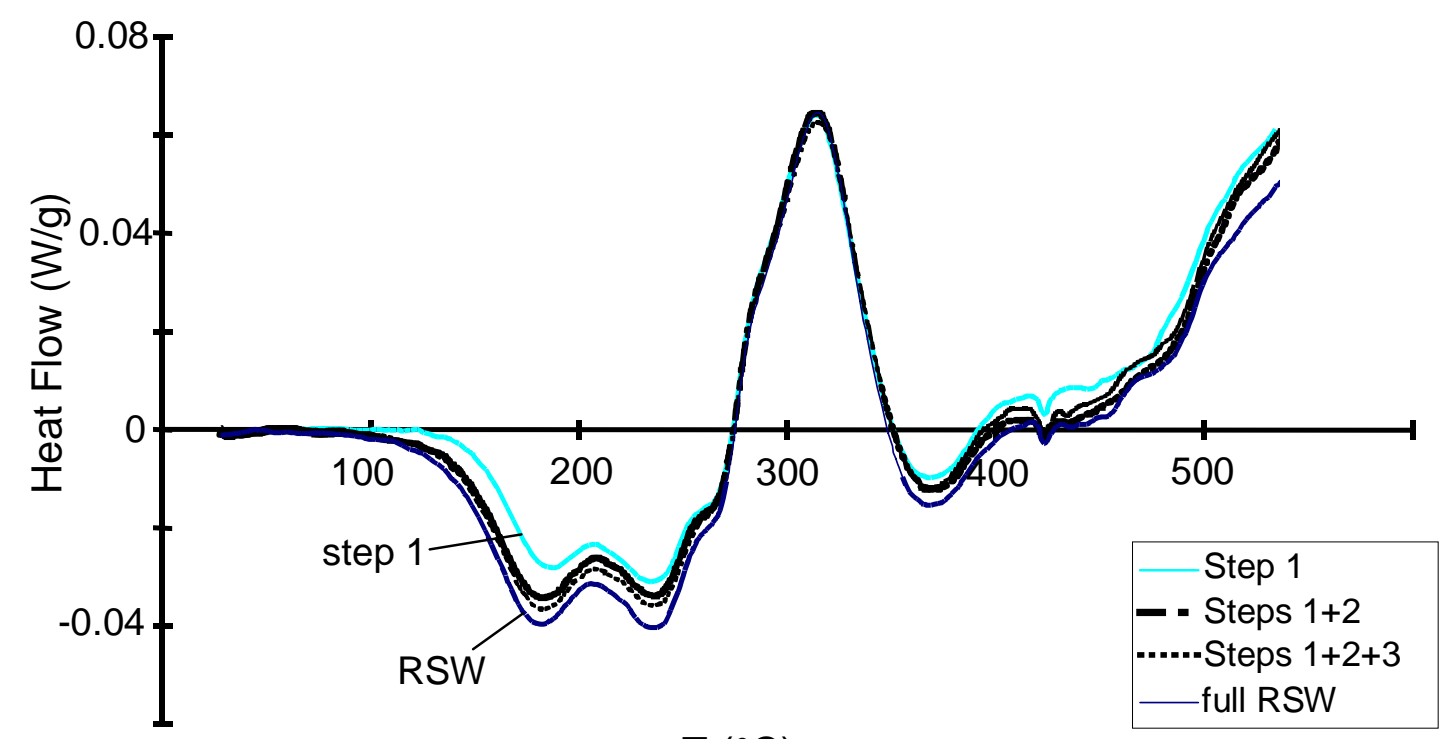

$\mathrm{T}\left({ }^{\circ} \mathrm{C}\right)$

Fig. 6 DSC curves of 8090 sheet subjected to the 4 subsequent steps that make up the RSW heat treatment.

The DSC traces for the $\mathrm{T} 81$ and $\mathrm{T} 81+\mathrm{X}$ samples (Fig. 7) show a common minimum at $230^{\circ} \mathrm{C}$. The exposed T81 sample displays a shoulder that has been shifted to a lower temperature. In comparing the DSC traces for the T81, T81+X, RSW and RSW+X samples it appears that exposure at slightly elevated temperature essentially causes an increase in the endothermic heat flow between 70 and $230^{\circ} \mathrm{C}$, but this occurs without significantly altering the overall shape of this low temperature part of the curves which is characterised by 2 endothermic peaks. This indicates that exposure at slightly elevated temperature does not lead to formation of new types of precipitates or the appearance of bimodal size distributions of any particular phase. In correspondence with this, TEM did not reveal bimodal size distributions of $\delta^{\prime}$ precipitates in any of these samples. 


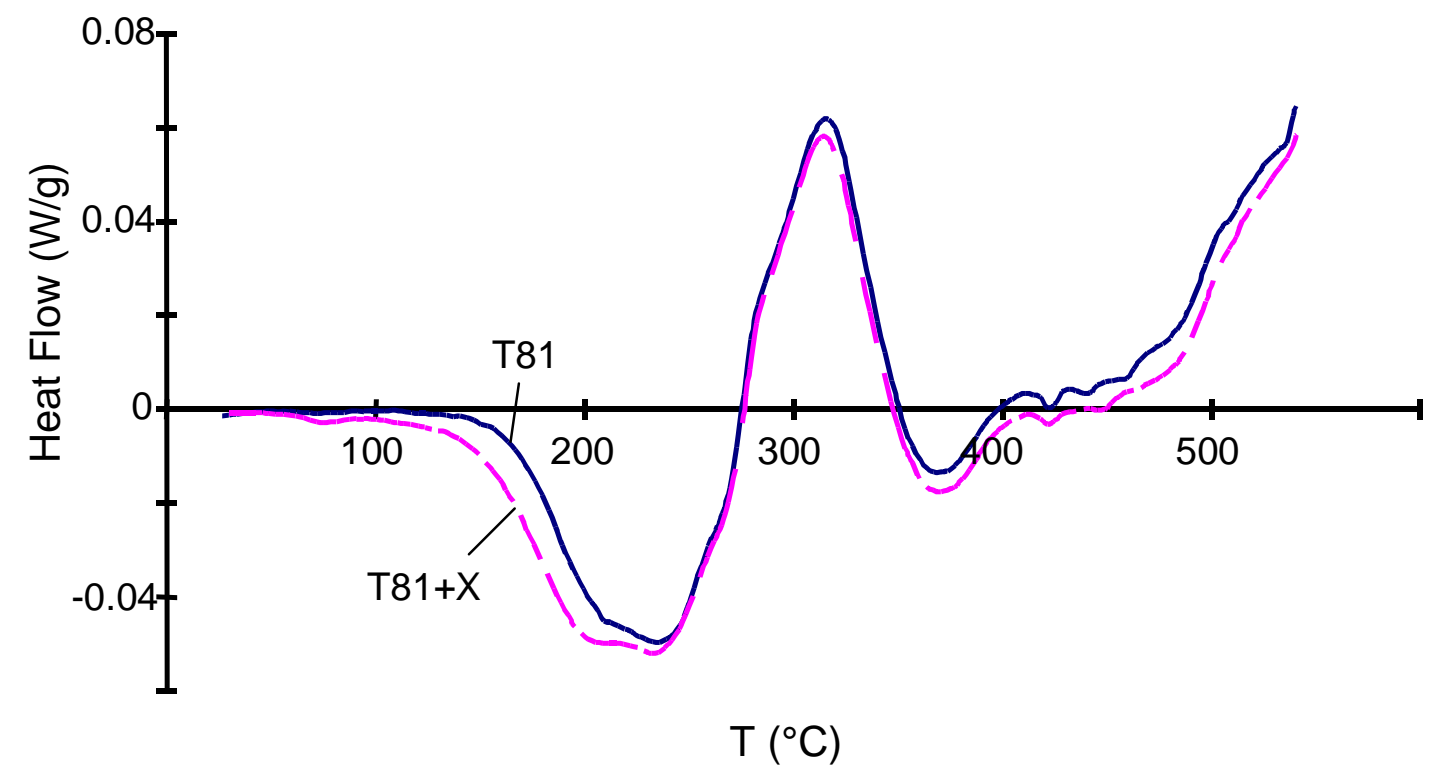

Fig. 7 DSC curves of $\mathrm{T} 81$ and $\mathrm{T} 81+\mathrm{X} 70^{\circ} \mathrm{C} 8090$ sheet.

\section{Analysis and Discussion}

\subsection{Quantitative analysis and model for strengthening}

To calculate the volume fractions of GPB zones and $\delta^{\prime}$ phase from the DSC curves, a procedure adopted before $[13,14]$ has been employed. For this calculation, first the total heat effect per unit volume of sample, $\Delta \mathrm{Q}_{\mathrm{d}}$, of the combined dissolution of GPB and $\delta^{\prime}$ in the range 50 to $260^{\circ} \mathrm{C}$ is calculated from the DSC graphs. This heat effect is the sum of the dissolution effects of GPB zones and $\delta$ ' phase, i.e.:

$$
\Delta \mathrm{Q}_{\mathrm{d}}=\Delta \mathrm{Q}_{\mathrm{GPB}, \mathrm{d}}+\Delta \mathrm{Q}_{\delta^{\prime}, \mathrm{d}}
$$

The amounts of GPB zones and $\delta^{\prime}$ phase present are given by:

$$
\begin{aligned}
& \mathrm{f}_{\mathrm{GPB}}=\frac{\Delta \mathrm{Q}_{\mathrm{GPB}, \mathrm{d}}}{\Delta \mathrm{H}_{\mathrm{GPB}}} \\
& \mathrm{f}_{\delta^{\prime}}=\frac{\Delta \mathrm{Q}_{\delta^{\prime}, \mathrm{d}}}{\Delta \mathrm{H}_{\delta^{\prime}}}
\end{aligned}
$$


where $\Delta \mathrm{H}_{\mathrm{GPB}}$ and $\Delta \mathrm{H}_{\delta^{\prime}}$ are the heats of formation (per unit volume of phase formed) and $\mathrm{f}_{\mathrm{GPB}}$ and $\mathrm{f}_{\delta^{\prime}}$ the volume fractions of GPB zones and $\delta^{\prime}$ phase, respectively [14].

The peaks due to the GPB zones and $\delta$ ' phase dissolution effects can not be separated and, hence, either $\mathrm{f}_{\mathrm{GPB}}$ or $\mathrm{f}_{\delta^{\prime}}$ will have to be estimated. As the heat treatments employed are all relatively long we can expect that the GPB zone formation is nearly completed, i.e. that the amount precipitated can be approximated by the solvus of the GPB zones. This procedure has been applied by estimating $\mathrm{f}_{\mathrm{GPB}}$ using the solvus of GPB in 8090 [19] and subsequently calculating $f_{\delta^{\prime}}$ using Eqs. 1-3. Results are presented in

Table 4. It is noted that whilst no increase in the size of $\delta^{\prime}$ phase nor the formation of additional small $\delta$ ' phase precipitates could be detected by TEM, the volume fractions of $\delta^{\prime}$ phase as calculated from the analysis of the DSC curves increase during exposure at $70^{\circ} \mathrm{C}$ both for the $\mathrm{T} 81$ and the RSW 8090. This indicates that, although not detected by TEM, limited growth of $\delta^{\prime}$ phase indeed occurred. Hence we will correct our measured $\delta$ ' phase sizes using:

$$
d_{\delta^{\prime}}(T 81+X)=d_{\delta^{\prime}}(T 81)\left[\frac{f_{\delta^{\prime}}(T 81+X)}{f_{\delta^{\prime}}(T 81)}\right]^{1 / 3}
$$

with an equivalent correction for the $\mathrm{RSW}+\mathrm{X}$ samples. This correction amounts to an increase of $d_{\delta}$ from $9 \mathrm{~nm}(\mathrm{~T} 81)$ to $9.8 \mathrm{~nm}(\mathrm{~T} 81+\mathrm{X})$, which, indeed, is largely undetectable by TEM. According to the model, the increase in strength resulting from the increase in average size (i.e. at constant total precipitate volume) is nearly negligible $(<2 \mathrm{MPa})$.

In the RSW and T3 alloys no significant $\mathrm{S}^{\prime}$ is expected to be present because ageing temperatures are too low and/or ageing times to short, but our previous results on 8090 MMCs [13] (i.e. 8090 containing a significant amount of misfit dislocations) suggest that T81 8090 may contain a very small amount of S' on dislocations. Indeed, the very small changes in the DSC heat effect due to S' formation on ageing at $150^{\circ} \mathrm{C}$ for up to $24 \mathrm{~h}$ (Fig. 4) indicate that a small amount of $\mathrm{S}^{\prime}$ is present in the T81 alloy. This amount is estimated using the analysis and model fits of $\mathrm{S}^{\prime}$ formation in monolithic 8090 presented in Ref. [13], employing a correction for the minor difference in temperature $\left(150^{\circ} \mathrm{C}\right.$ in for the present $\mathrm{T} 81$ treatment vs. $170^{\circ} \mathrm{C}$ in Ref. [13]) as outlined in Ref. [11]. This yields an $\mathrm{S}^{\prime}$ content of 0.04 vol\%, which causes a modest increase in yield strength of about 40 MPa. 
Using the precipitate volumes and sizes obtained from the analysis outlined above, the yield strengths of the 8090 sheet alloys in the various heat treated conditions were calculated using a model outlined in detail in a previous paper [20]. The model and associated parameters are outlined briefly in the Appendix and final predicted yield strengths are presented in

Table 4. These model predictions are in reasonable agreement with the measured yield strengths, thus confirming that our interpretation is essentially sound. Notwithstanding the reasonable overall agreement of experimental data and model predictions, other factors, not explicitly included in the model, may contribute to the changes in mechanical properties during exposure at slightly elevated temperature. Two mechanisms are especially highlighted: variation of Taylor factor and minor changes in the order within the $\delta^{\prime}$ phase. The Taylor factor, $M$, is sensitive to the degree of stress localisation and/or the number of slip systems operating in a grain [20,21]. Both can be influenced to some degree by $\delta^{\prime}$ phase precipitation and growth and, hence, ageing can result in (limited) variations in $M$. Further, improved ordering within the $\delta^{\prime}$ phase and changes of the $\delta^{\prime} /$ matrix interface can cause an additional hardening increment. The changes in strengthening efficiency of $\delta$ ' phase as a result of changes in degree of ordering have been commented on before [22].

It is noted that the volume fractions of $\delta^{\prime}$ phase in artificially aged samples exposed at $70^{\circ} \mathrm{C}$ calculated from the DSC data are higher than the saturation values that can be obtained from the (metastable) solubility data for Li in 8090 in Ref. [16], which is the only data on the $\delta$ ' phase solvus in 8090 (according to our calculations $\mathrm{f}_{\delta^{\prime}}$ is about $22 \mathrm{vol} \%$ vs. about $13 \mathrm{vol} \%$ according to the solvus data published in Ref. [16]). As this may potentially undermine our present interpretation we repeated the above analysis, but instead of using the GPB solvus as a starting point for the calculations we now assumed full $\delta^{\prime}$ phase formation and used the solvus data in Ref. [16]. This procedure yields somewhat different volume fractions of $\delta^{\prime}$ phase and GPB zones, and final yield strength predictions overestimate the measured yield strength by about $20 \mathrm{MPa}$ (see Table 5). Whilst this deviation may be considered quite limited, the position of the low temperature solvus of $\delta^{\prime}$ phase does influence the analysis of the relative importance of $\delta^{\prime}$ and GPB formation in the total strengthening. Thus, to analyse this relative importance, the data on the low temperature solvus of $\delta^{\prime}$ phase in Al-Li-Cu-Mg type alloys needs to be investigated more closely.

The main points in the relevant literature on the low temperature solvus of $\delta$ ' phase in Al-Li-Cu-Mg type alloys can be summarised as follows:

1. Addition of $\mathrm{Cu}$ or $\mathrm{Zr}$ to Al-Li has no significant influence on the solvus of $\delta^{\prime}$ phase [23,24]. 
2. Addition of $\mathrm{Mg}$ to Al-Li has a very minor effect on the solvus of $\delta^{\prime}$ phase. Some researchers have detected a minor decrease of the solvus [23,25], whilst others have detected a minor increase [26].

3. The metastable solubility of $\mathrm{Li}$ at room temperature has been reported as $5 \mathrm{at} \%$ (Schiffini and co-workers [27,28]) and 2.3 at\% [29] for binary Al-Li and as 5.4at\% [16] and 1.6at\% [17] for quaternary Al-Li-Cu-Mg alloys.

4. The low temperature $\left(<90^{\circ} \mathrm{C}\right)$ solvus of binary Al-Li in Refs. [30,31] is based on a single data point obtained using SAXS on a sample aged for $200 \mathrm{~h}$ at $20^{\circ} \mathrm{C}$ by Ceresara et al. [27]. This solvus indicates a solubility of $5.3 \mathrm{at} \% \mathrm{Li}$ at $70^{\circ} \mathrm{C}$, which is inconsistent with our results.

5. The low temperature $\left(<90^{\circ} \mathrm{C}\right.$ ) solvus data for 8090 (Al-Li-Cu-Mg) in Ref. [16] is based on a single data point obtained using SANS on a sample aged at $20^{\circ} \mathrm{C}$. Ageing time is not reported. The solvus indicates a solubility of about $5.7 \mathrm{at} \% \mathrm{Li}$ at $70^{\circ} \mathrm{C}$, which is inconsistent with our results.

6. The solvus of binary Al-Li in Refs. [24] indicates a solubility of $2.7 \mathrm{at} \% \mathrm{Li}$. at $70^{\circ} \mathrm{C}$. This latter solvus is based on simple regular solution expression, with the entropy of mixing and the heat of mixing fitted to an extensive range of solubility data in the temperature range $70-400^{\circ} \mathrm{C}$. This solvus is in line with our results.

7. The solvus of binary Al-Li in Refs. [32,33] indicates a solubility of $3.2 \mathrm{at} \% \mathrm{Li}$ at $70^{\circ} \mathrm{C}$. This latter solvus is based on a thermodynamic model of the ordered phase, with the interaction parameters fitted to solubility data in the temperature range $110-350^{\circ} \mathrm{C}$ and it is in line with our results.

8. The low temperature solvus of binary Al-Li in Ref. [34] is based on cluster variation technique, with the interaction parameters fitted to solubility data in the temperature range $110-350^{\circ} \mathrm{C}$. As the low temperature solubility in Ref. [34] (1at\%Li at $70^{\circ} \mathrm{C}$ ) is doubtful [24], and inconsistent with all experimental data and theoretical modelling we will disregard this low temperature solvus.

In comparing the above data and interpretations it is apparent that inconsistencies exist. Assuming that the effects of $\mathrm{Cu}$ and $\mathrm{Mg}$ addition on the solvus of $\delta^{\prime}$ phase is limited [23,25], our present results support the low temperature $\left(<100^{\circ} \mathrm{C}\right)$ solvus suggested by Khachaturyan et al. [32,33] as well as the similar one presented by Noble and Bray [24], and it appears that the solvi in Refs. [16,30] significantly overestimate the solubility of Li in the 8090 alloy and in Al-Li alloys. An explanation for the inconsistencies may be that in the samples aged at $20^{\circ} \mathrm{C}$ which were used to define the low temperature solvus in Refs. [16,30], $\delta^{\prime}$ phase formation was incomplete. Justification of this suggestion may be found in our observation that ageing of 8090 for more than one year at room temperature is not sufficient to complete precipitation (in Ref. [30] a sample aged for $200 \mathrm{~h}$ at 
$20^{\circ} \mathrm{C}$ was employed). The metastable equilibrium amounts of GPB zones and $\delta^{\prime}$ phase in our 8090 samples as obtained from the solvus data in Refs. $[19,24]$ is presented in Fig. 1. This solvus data is consistent with our assessments. 


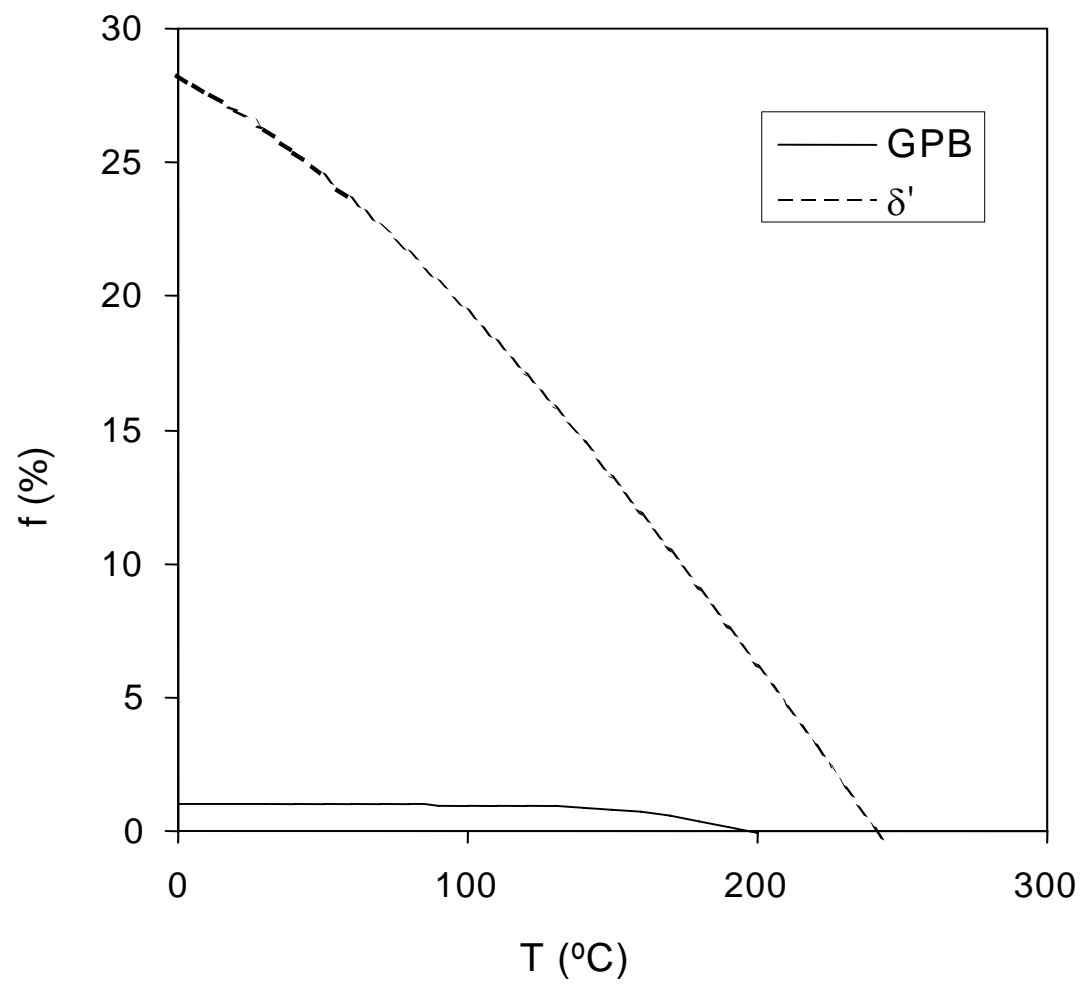

Fig. 1 Equilibrium volume fractions of GPB zones and $\delta$ ' phase in our 8090 (sheet) samples as obtained from the solvus data in Refs. [19,24].

Work hardening is caused by the presence of non-shearable obstacles to dislocation motion, such as grain boundaries and strong particles. Thus, in the present underaged 8090 alloys, work hardening is caused mainly by grain boundaries and $\beta^{\prime}\left(\mathrm{Al}_{3} \mathrm{Zr}\right)$ [13], but largely uninfluenced by shearable GPB zones, $\delta^{\prime}$ or small $\mathrm{S}^{\prime}$ precipitates. As grain structure and $\beta^{\prime}\left(\mathrm{Al}_{3} \mathrm{Zr}\right)$ are largely uninfluenced by artificial ageing at $70^{\circ} \mathrm{C}$ this exposure has no significant influence on the work hardening exponent (see Tables 2 and 3), even though significant changes in the sizes and volume fractions of GPB zones and $\delta^{\prime}$ occurs. The difference between the work hardening exponents in $\mathrm{T}$ and $\mathrm{L}$ direction is thought to be related to texture or the shape of the grains (elongated in the $\mathrm{L}$ direction).

\subsection{Mechanisms of embrittlement}

Fractography of the 8090 sheet toughness specimens (Fig. 1) reveals no evidence of grain boundary embrittlement due to exposure. This refutes earlier suggestions [5] that embrittlement on exposure at slightly elevated temperatures could be due to segregation of lithium atoms to the grain boundaries. Instead, failure seems to be dominated by intragranular ductile shear failure in strongly underaged tempers (T3) and more strongly defined shear decohesion with occasional grain boundary failure in artificially aged tempers (RSW, T81). This transformation of failure mode in 
the unexposed material is as would be expected for tempers of increasing strength. Although the exposed materials might have been expected to show some evidence of increased slip planarity due to the increase in volume fraction of $\delta^{\prime}$ particles, the fractographs in fact indicate that no significant change in the relative importance of the fracture modes occurs. This indicates that the changes in volume fraction of $\delta^{\prime}$ particles on exposure at slightly elevated temperature reduce the resistance to both ductile shear failure and shear decohesion to a similar extent. For RSW and T81 8090 material, the relative insensitivity of observed fracture modes to exposure can further be discussed in terms of the critical $\delta^{\prime}$ diameter for the occurrence of slip planarity, $d_{c}$, as identified in the works of Blankenship et al. [35,36]. In these works it is shown that $d_{c}$ is proportional to $L \sqrt{f r}$, where $L$ is the slip length. In the present samples the amount of $S^{\prime}$ is too low to effectively cause slip dispersion, and, hence, L can be estimated to equal the subgrain size ( $2 \mu \mathrm{m}$, see Refs. $[11,13])$, and from the data in

Table $4 \mathrm{~d}_{\mathrm{c}}$ is estimated to range from $44 \mathrm{~nm}$ for RSW to $64 \mathrm{~nm}$ for T81+X material. Due to the very limited variation in $L \sqrt{f r}$, the ratio $d_{c} / d$, which can be considered to be a measure of the propensity for planar slip [35], changes very little in the artificial (under)ageing and exposure treatments considered. This explains why the fracture surfaces change very little during these treatments: the propensity for planar slip is not significantly altered. From the above it appears that the decrease in toughness is closely related to the increase in the critical resolved shear stress (CRSS) of the grains. Thus strength changes are thought to be mainly due to the formation of additional $\delta^{\prime}$ phase and toughness changes because toughness generally decreases monotonically with increasing strength.

On the latter point it should be noted that in some specific cases, variations in the toughness levels are possible for one single yield strength are possible. This is specifically illustrated by double aged 8090 for which the strength-toughness combinations are enhanced as compared to underaged alloys [35,37]. Additional work by the present authors [38] has further shown that strengthtoughness combinations of 8090 aged for 6 years at room temperature (T3(6y)) can be improved by flash reversion $\left(5 \mathrm{~min}\right.$ at $190^{\circ} \mathrm{C}$ ), and even after a subsequent exposure for $1000 \mathrm{~h}$ at $70^{\circ} \mathrm{C}$ strengthtoughness combinations are better than in the T3(6y) condition. Explanations for the enhanced strength-toughness combinations in these works is thought to lie in the occurrence of a significant amount of slip dispersing S' precipitates (which decreases $L$ and thus decreases the propensity for planar slip), enhanced work hardening, dissolution of fine $\delta^{\prime}$ phase (which reduces $f$, thus yielding a decrease in the propensity for planar slip) and/or bimodal size distributions of $\delta$ ' phase. It is noted that these features appear in alloys with yield strengths in the range of 300 to $400 \mathrm{MPa}$ and will 
generally be less important or absent in the very underaged microstructures considered in the present work (yield strengths 170-340MPa).

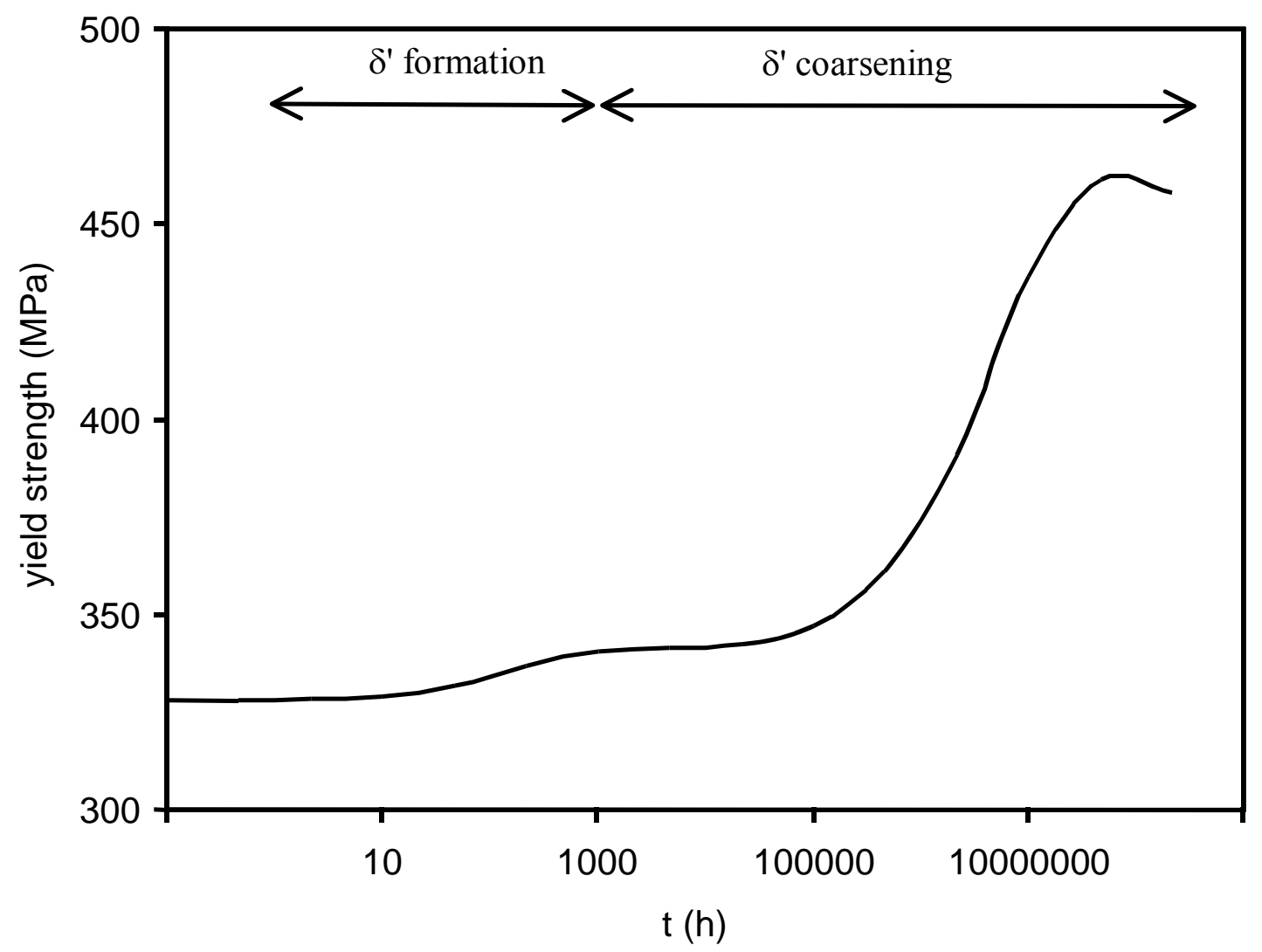

Fig. 1 Predicted strengthening during exposure of T81 8090 using the strengthening model (Appendix 1) combined with estimates for microstructure changes based on the StarinkZahra model [47] and the LSW model (see Appendix 2).

Table 4 Strengthening increments due to $\delta^{\prime}$ and GPB as predicted by the model (see text) compared with the measured strength. (Values in brackets are for the unrealistic case of $\delta^{\prime}$ in the naturally aged condition being fully effective in strengthening the alloy, see appendix.)

\begin{tabular}{lccccccc}
\hline Ageing Treatment & $\begin{array}{c}\mathrm{d}_{\delta^{\prime}} \\
(\mathrm{nm})\end{array}$ & $\begin{array}{c}\mathrm{f}_{\delta^{\prime}} \\
(\mathrm{vol} \%)\end{array}$ & $\begin{array}{c}\mathrm{f}_{\mathrm{GPB}} \\
(\mathrm{vol} \%)\end{array}$ & $\begin{array}{c}\Delta \tau_{\delta^{\prime}} \\
(\mathrm{MPa})\end{array}$ & $\begin{array}{c}\Delta \tau_{\mathrm{GPB}} \\
(\mathrm{MPa})\end{array}$ & $\begin{array}{c}\sigma_{0.2} \text { (model) } \\
(\mathrm{MPa})\end{array}$ & $\begin{array}{c}\sigma_{0.2}(\exp ) \\
(\mathrm{MPa})\end{array}$ \\
\hline $\mathrm{T} 3$ & 2 & 15.7 & 0.98 & 20 & 37 & $200(226)$ & 201 \\
$\mathrm{~T} 3+1000 \mathrm{~h}$ at $70^{\circ} \mathrm{C}$ & 4 & 11.9 & 0.979 & 25 & 37 & 237 & 245 \\
$\mathrm{RSW}$ & 6 & 17.1 & 0.973 & 36 & 37 & 271 & 267 \\
$\mathrm{RSW}+1000 \mathrm{~h}$ at $70^{\circ} \mathrm{C}$ & 6.5 & 21.4 & 0.979 & 42 & 37 & 282 & 299 \\
\hline
\end{tabular}




\begin{tabular}{lccccccc}
\hline Ageing Treatment & $\mathrm{d}_{\delta^{\prime}}$ & $\mathrm{f}_{\delta^{\prime}}$ & $\mathrm{f}_{\mathrm{GPB}}$ & $\Delta \tau_{\delta^{\prime}}$ & $\Delta \tau_{\mathrm{GPB}}$ & $\sigma_{0.2}$ (model) & $\begin{array}{c}\sigma_{0.2}(\exp .) \\
(\mathrm{nm})\end{array}$ \\
\hline $\mathrm{vol} \%)$ & $(\mathrm{vol} \%)$ & $(\mathrm{MPa})$ & $(\mathrm{MPa})$ & $(\mathrm{MPa})$ & $(\mathrm{MPa})$ \\
\hline $\mathrm{T} 81$ & 9 & 16.8 & 0.795 & 44 & 33 & 324 & 318 \\
$\mathrm{~T} 81+1000 \mathrm{~h}$ at $70^{\circ} \mathrm{C}$ & 9.8 & 21.8 & 0.979 & 52 & 37 & 343 & 336 \\
\hline
\end{tabular}

Table 5 Strengths as predicted by the model (see text) using two methods of calculating the amounts of $\delta^{\prime}$ and GPB: a) by estimating GPB fractions from the GPB solvus, and b) by estimating $\delta^{\prime}$ fractions from the $\delta^{\prime}$ solvus in Ref. [16]. (Values in brackets are for the unrealistic case of $\delta^{\prime}$ in the naturally aged condition being fully effective in strengthening the alloy.)

\begin{tabular}{lcccc}
\hline Ageing Treatment & $\begin{array}{c}\mathrm{d}_{\delta^{\prime}} \\
(\mathrm{nm})\end{array}$ & $\begin{array}{c}\sigma_{0.2}(\mathrm{GPB} \text { solvus }) \\
(\mathrm{MPa})\end{array}$ & $\begin{array}{c}\sigma_{0.2}\left(\delta^{\prime} \text { solvus }[16]\right) \\
(\mathrm{MPa})\end{array}$ & $\begin{array}{c}\sigma_{0.2}(\mathrm{exp} .) \\
(\mathrm{MPa})\end{array}$ \\
\hline $\mathrm{T} 3$ & 2 & $208(235)$ & $228(253)$ & 201 \\
$\mathrm{~T} 3+1000 \mathrm{~h}$ at $70^{\circ} \mathrm{C}$ & 4 & 246 & 261 & 245 \\
$\mathrm{RSW}$ & 6 & 286 & 293 & 267 \\
$\mathrm{RSW}+1000 \mathrm{~h}$ at $70^{\circ} \mathrm{C}$ & 6.5 & 298 & 303 & 299 \\
$\mathrm{~T} 81$ & 9 & 324 & 343 & 318 \\
$\mathrm{~T} 81+1000 \mathrm{~h}$ at $70^{\circ} \mathrm{C}$ & 9.8 & 345 & 362 & 336 \\
\hline
\end{tabular}

\subsection{Reducing sensitivity of Al-Li based alloys to low-temperature embrittlement}

Our current interpretation (

Table 4) rationalises the present microstructure data (TEM and DSC) and proof stress data as well as conflicting literature data on the low temperature solvus of $\delta^{\prime}$. Thus, the present analysis based on the strengthening model indicates that changes in proof stress up to $1000 \mathrm{~h}$ exposure at $70^{\circ} \mathrm{C}$ are related mostly to changes in the volume fractions and sizes of the established zones/precipitates: GPB zones and $\delta^{\prime}$ precipitates. For the present underaged alloys $\left(\sigma_{0.2}<340 \mathrm{MPa}\right)$, the decrease in toughness is thought to be directly linked to the increase in yield strength via the established toughness-strength relations for underaged 8090 [4]. It is further noted that additional experiments (results not presented) have shown that the observed toughness changes in the underaged 8090 as well as $1441 \mathrm{Al}-\mathrm{Li}$ based plate alloys are reversible, i.e. a short reversion treatment (5 min at $190^{\circ} \mathrm{C}$ ) after exposure at $70^{\circ} \mathrm{C}$ restores the toughness of the alloys to pre-exposure levels, whilst a 
subsequent second exposure reduces the toughness again to pre-reversion levels. These T8exposure-reversion-reexposure experiments further show that for the present exposures (up to $1000 \mathrm{~h}$ at $70^{\circ} \mathrm{C}$ ) embrittlement is unlikely to be related to Ostwald ripening (i.e. coarsening at nearly constant volume fraction) as this process is not reversible.

It is further noted that whilst the present analysis indicates that for RSW and T851 exposed up to $1000 \mathrm{~h}$ at $70^{\circ} \mathrm{C}$ Ostwald ripening is not an important factor, this process will cause significant additional hardening on more extended exposure [4,39]. To illustrate the potential for further hardening due to Ostwald ripening the microstructure development during exposure at $70^{\circ} \mathrm{C}$ has been estimated using literature data, and this microstructural data has been used as input to our strengthening model. This procedure is outlined in Appendix 2 and the resulting graph of strengthening (Fig. 1) illustrates that hardening of 8090 at $70^{\circ} \mathrm{C}$ is a two-stage process consisting of precipitation followed by coarsening. The potential for hardening due to coarsening is very large $(>100 \mathrm{MPa})$, but the rate of hardening is very low: to achieve half of the hardening several years of exposure at $70^{\circ} \mathrm{C}$ are necessary.

Table 6 Comparison of the critical $\delta^{\prime}$ diameter for the occurrence of slip planarity, $\mathrm{d}_{\mathrm{c}}$, with the actual diameter of $\delta^{\prime}, \mathrm{d}_{\delta^{\prime}}$.

\begin{tabular}{lccc}
\hline Ageing Treatment & $\begin{array}{c}\mathrm{d}_{\delta^{\prime}} \\
(\mathrm{nm})\end{array}$ & $\begin{array}{c}\mathrm{d}_{\mathrm{c}} \\
(\mathrm{nm})\end{array}$ & $\begin{array}{c}\mathrm{d}_{\delta^{\prime}} / \mathrm{d}_{\mathrm{c}} \\
(\mathrm{nm})\end{array}$ \\
\hline $\mathrm{T} 3$ & 2 & 24.7 & 12.3 \\
$\mathrm{~T} 3+1000 \mathrm{~h}$ at $70^{\circ} \mathrm{C}$ & 4 & 30.4 & 7.6 \\
$\mathrm{RSW}$ & 6 & 44.5 & 7.4 \\
$\mathrm{RSW}+1000 \mathrm{~h}$ at $70^{\circ} \mathrm{C}$ & 6.5 & 50.1 & 8.3 \\
$\mathrm{~T} 81$ & 9 & 54.2 & 6.0 \\
$\mathrm{~T} 81+1000 \mathrm{~h}$ at $70^{\circ} \mathrm{C}$ & 9.8 & 63.7 & 6.6 \\
\hline
\end{tabular}

The present analysis indicates three ways in which the sensitivity to embrittlement during exposure at slightly elevated temperature of Al-Li-Cu-Mg alloys can be reduced:

- Applying an RSW type ageing treatment. This will ensure that the driving force for additional $\delta^{\prime}$ phase formation during stage I is low whilst $\delta^{\prime}$ phase precipitates are smaller than in T81 alloys. Especially the latter is beneficial because it causes the strengthening during stage I to be 
limited as compared with the T81 alloys. The present analysis indicates, however, that during stage II hardening coarsening will cause $\delta^{\prime}$ particle sizes to converge for all heat treated 8090 alloys and hence the benefits of RSW treatments will eventually be lost.

- Reducing the amount of $\delta^{\prime}$ phase that can form at $70^{\circ} \mathrm{C}$ through reduction of the Li content. This will ensure that i) the driving force for additional $\delta^{\prime}$ phase formation during stage I is low, and ii) the maximum hardening achievable during stage II is limited. As a result hardening and the concomitant embrittlement at $70^{\circ} \mathrm{C}$ will be slow in both stage I and II.

- Increasing the amount of GPB zones that can form through increasing the $\mathrm{Cu}$ and $\mathrm{Mg}$ contents, whilst reducing the $\mathrm{Li}$ content to maintain the same initial strength levels. As the strengthening increment due to GPB zones is proportional to $f_{\mathrm{GPB}}{ }^{1 / 2}$ the relative importance of additional strengthening due to additional GPB formation at $70^{\circ} \mathrm{C}$ is reduced for alloys with higher $\mathrm{Cu}$ and $\mathrm{Mg}$ contents. More importantly, the relative importance of additional strengthening due to additional $\delta^{\prime}$ phase formation (stage I hardening) and $\delta^{\prime}$ phase coarsening (stage II hardening) is much reduced for alloys with higher $\mathrm{Cu}$ and $\mathrm{Mg}$ contents because superposition of strengthening contributions, $\tau_{i}$, is given by:

$$
\left(\Delta \tau_{\Sigma}\right)^{q}=\sum_{i=1}^{M}\left(\Delta \tau_{i}\right)^{q}
$$

with $q>1$ (see Appendix and Ref. [40]).

The effectiveness of the first modification can be illustrated by the mechanical property data on exposed RSW 8090 (Fig. 1) and by work on RSW 8090 by Vine et al. [4]. Reducing the Li content of 8090 has been employed, leading to the so-called ALFSOTATS alloy, and his modification has been shown to be effective in reducing embrittlement [4]. Additional experiments on 1441 (Al2.0Li-1.8Cu-0.85) plate alloys showed that embrittlement after exposure for $1000 \mathrm{~h}$ at $70^{\circ} \mathrm{C}$ is less pronounced than for 8090 plate.

\section{Conclusions}

Rolled 8090 sheet in three underaged heat treatment conditions, including T3, T81 and a multi stage temper designated RSW, was exposed for $1000 \mathrm{~h}$ at $70^{\circ} \mathrm{C}$. The fine microstructures developed during the ageing treatments and subsequent thermal exposure were studied quantitatively via differential scanning calorimetry and transmission electron microscopy. The following conclusions were drawn:

- Exposure of T3, T81 and RSW 8090 material at $70^{\circ} \mathrm{C}$ causes an increase in yield strength and a decrease in toughness. Toughness reduction is limited for the RSW condition. 
- Available evidence suggests that the low temperature DSC effects in T3 and RSW comprise of dissolution of fine $\delta^{\prime}$ which becomes unstable on heating in the DSC, coarsening of $\delta^{\prime}$, and, finally, dissolution of coarser $\delta^{\prime}$ and GPB. No direct evidence of $\delta^{\prime}$ precursors was detected.

- The effect of exposure for $1000 \mathrm{~h}$ at $70^{\circ} \mathrm{C}$ on $\mathrm{T} 3$ material is to reduce the volume fraction of $\delta^{\prime}$ and to increase the $\delta$ ' particle diameter from $2 \mathrm{~nm}$ to $4 \mathrm{~nm}$.

- The effect of exposure for $1000 \mathrm{~h}$ at $70^{\circ} \mathrm{C}$ on RSW and T81 is to primarily increase the volume fractions of $\delta^{\prime}$ and GPB zones.

- Quantitative analysis of the DSC data in combination with a comprehensive model for strengthening of Al-Li-Cu-Mg-Zr type alloys shows that observed changes in properties can be explained in terms of the measured changes in the volume fractions of $\delta^{\prime}$ and GPB zones.

- Compared to the standard T8 temper, 8090 in the RSW condition is more stable on exposure at $70^{\circ} \mathrm{C}$.

- Many conflicting data on the low temperature solvus of $\delta^{\prime}$ in Al-Li and Al-Li-Cu-Mg has appeared in the literature. Our data is consistent with the solvus presented by Khachaturyan $[32,33]$ as well as the similar one presented by Noble and Bray [24].

\section{Acknowledgements}

The technical collaboration of Mr H.J. Price of BAE Systems (currently Military Aircraft \& Aerostructures) and the financial support of the Company are gratefully acknowledged.

\section{Appendix 1: Strengthening model}

Calculations were made to estimate the expected strengthening in the 8090 alloy for the various heat treatment conditions studied. These calculations were based on a comprehensive model described elsewhere [20], which takes precipitate strengthening (by GPB zones, $\delta^{\prime}$ and $\mathrm{S}^{\prime}$ ), solution strengthening (by $\mathrm{Cu}, \mathrm{Mg}$ and $\mathrm{Li}$ ), grain and sub-grain strengthening and dislocation hardening into account. For the present alloys GPB zone and $\delta^{\prime}$ phase are the main strengthening components and, hence, we will briefly describe how the strength contribution of these two phases are modelled.

\section{Strengthening due to $\delta^{\prime}$}

We base our analysis on the expressions presented in Refs. [41,42,43], which yield good fits to measured CRSS of Al-Li single crystals and which appear to be consistent with data on the 
interaction between dislocation and precipitate [41,42]. For precipitates in an underaged state the appropriate expression for order hardening is [43]:

$$
\Delta \tau_{\text {ord, ua }}=\frac{\gamma_{\text {apb }}}{2 \mathrm{~b}}\left(\sqrt{\frac{3 \pi^{2} \gamma_{\mathrm{apb}} \mathrm{f}_{\delta^{\prime}}<\mathrm{r}>}{32 \Gamma}}\right)
$$

$\gamma_{a p b}$ is the anti phase boundary energy on $\{111\}$ planes, $\langle r>$ is the average radius of the precipitates and $\Gamma$ is the line tension, which can be calculated using the expressions presented in Ref. [43]. When precipitates are relatively large and strong and the alloy is near its peak aged condition the appropriate expression for order hardening is [43]:

$$
\Delta \tau_{\text {ord,pa }}=0.81 \frac{\gamma_{\mathrm{apb}}}{2 \mathrm{~b}}\left(\sqrt{\frac{3 \pi \mathrm{f}_{\delta^{\prime}}}{8}}\right)
$$

The change-over from the weak particle to the strong particle regime is relatively abrupt [42] and hence the total strengthening due to order hardening can be obtained to a sufficient accuracy by:

$$
\Delta \tau_{\text {ord }}=\operatorname{Min}\left\{\Delta \tau_{\text {ord,ua }}, \Delta \tau_{\text {ord }, p a}\right\}
$$

We further need to take account of the fact that the very fine $\delta^{\prime}$ phase that forms on room temperature ageing has a near to negligible strengthening effect [22]. This deviation from the predictions of the above equations is thought to result from their reduced effectiveness as obstacles as a result of their diffuse interface [14] and other structural imperfections $[22]^{\dagger}$. We will model strength for this condition assuming that the strengthening effect of $\delta^{\prime}$ phase in the room temperature aged condition is effectively zero. (In the table with results of the model (

Table 4) the case of full effective $\delta$ ' phase strengthening is presented in brackets.)

\section{Strengthening due to GPB zones}

GPB zones are thought to strengthen crystals mainly as a result of modulus strengthening, and a simplified expression for this type of strengthening is given by [17]:

$$
\Delta \tau_{\text {mod }}=\frac{\Delta \mathrm{G}}{4 \pi \sqrt{2}} \sqrt{\mathrm{f}_{\mathrm{GPB}}}
$$

\footnotetext{
${ }^{\dagger}$ Strengthening due to $\delta$ ' phase is a result of order hardening and hence the anti-phase boundary (APB) energy of the $\mathrm{L}_{2}$ ordered phase is the determining factor for strengthening. If boundaries are diffuse, ordering in part of the $\delta^{\prime}$ precipitate is not complete, and the average APB energy of a section through the precipitate is lower than in fully ordered $\delta^{\prime}$ phase. Hence, diffuse interfaces will reduce strengthening.
} 
where $\Delta \mathrm{G}$ is the difference in shear moduli of matrix and GPB zone (see $[17,20])$.

\section{Superposition of the strengthening effects}

The superposition of the strengthening effects is calculated using expressions of the type:

$$
\left(\Delta \tau_{\Sigma}\right)^{q}=\sum_{i=1}^{M}\left(\Delta \tau_{i}\right)^{q}
$$

The various values of $q$ which are appropriate for the superposition of different strengthening effects have been outlined elsewhere [20]. For superposition of GPB zone and $\delta^{\prime}$ phase strengthening $q \approx 1.23$.

\section{Deformation of polycrystalline textured monolithic alloys.}

The (macroscopic) yield strength of a polycrystalline metal has been related to the critical resolved shear stress (CRSS), $\Delta \tau_{\Sigma}$, of the crystals via various models, which generally yield an equation of the type:

$$
\sigma_{\mathrm{y}}=\mathrm{M} \Delta \tau_{\Sigma}
$$

Where $M$ is a constant (sometimes referred to as the Taylor factor). The lower bound solution for $M$ is given by the Sachs model (for texture free FCC metals: $M_{S}=2.24$ ) and the upper bound solution for $M$ is given by the Taylor model (for texture free FCC metals: $M_{T}=3.07$ ) [44]. Self-consistent models [21], yield intermediate values for $M$; for texture free FCC metals Hutchinson's [21] selfconsistent model gives $M \cong 2.6$. In Al-Li based alloys containing only $\delta^{\prime}$ precipitates slip tends to be localised in bands, and S' tends to cause a more homogeneous slip. In the present work we will incorporate a change from heterogeneous to homogeneous slip by approximating the effective $M$ as the average of $M_{\mathrm{T}}$ and $M_{\mathrm{S}}$ weighted by the strengthening contributions due to $\mathrm{S}^{\prime}$ and $\delta^{\prime}$ :

$$
\mathrm{M}=\frac{\mathrm{M}_{\mathrm{T}} \Delta \tau_{\mathrm{S}^{\prime}}+\mathrm{M}_{\mathrm{S}} \Delta \tau_{\delta^{\prime}}}{\Delta \tau_{\mathrm{S}^{\prime}}+\Delta \tau_{\delta^{\prime}}}
$$

Following the weighting methods for texture components outlined in Ref. [44] combined with texture data in Refs. $[44,45]$ it is calculated that for hot rolled monolithic 8090 sheet $M_{T}=3.2$ and $M_{S}=2.55$. For monolithic 8090 alloy this procedure yields $M$ values ranging from 2.55 for $\mathrm{S}^{\prime}$ free T3 alloys to 2.64 and 2.95 for alloys containing increasing amounts of S'.

In order to perform the strength calculations the strengthening resulting from (the dislocation structure introduced by) the $2 \%$ stretch is estimated from tensile tests on naturally aged 8090 (46). This yields a proof stress increment of about $70 \mathrm{MPa}$. 


\section{Appendix 2: Microstructure development during ageing at $70^{\circ} \mathrm{C}$.}

To illustrate the two stage nature of hardening, the microstructure development during exposure at $70^{\circ} \mathrm{C}$ has been estimated using literature data. The amount of $\delta^{\prime}$ phase formed was assumed to be given by the Starink-Zahra model $[47,48]$, the relevant model parameters were estimated from data for similar reactions (yielding reaction exponent $n \approx 1$ and impingement parameter $\eta_{i} \approx 2$ ) and by assuming $\delta^{\prime}$ phase formation to be $95 \%$ completed at $\mathrm{t}=1000 \mathrm{~h}$. Coarsening of $\delta^{\prime}$ phase has been calculated using the LSW coarsening model (see e.g. Ref. [4]), using coarsening data in Ref. [11] in combination with an activation energy for coarsening estimated at $74 \mathrm{~kJ} / \mathrm{mol}$ [15].

\section{References}

1 I. Sinclair and P.J. Gregson, Scripta Metall. Mater. 30 (1994) 1287.

2 P.D. Pitcher, D. McDarmaid, C.J. Peel and G. Hall, in: M. Peters and P.J. Winkler (Eds.), Proc. Al-Li alloys VI, DGM Metallurgy Information, New York, USA, 1992, p. 235.

3 C.J. Peel, in: M. Peters and P.J. Winkler (Eds.), Proc. Al-Li alloys VI, DGM Metallurgy Information New York, USA, 1992, p. 1259.

4 W.J. Vine, G.R. Sutton and H.J. Price, in: T. Sato, S. Kumai, T. Kobayashi and Y. Murakami (Eds.) Proc. of ICAA-6, Toyohashi, Japan, 1998, p. 1973

$5 \quad$ S.P. Lynch, A.R. Wilson and R.T. Byrnes, Mater. Sci. Eng. A172 (1993) 79.

6 B. Noble, S.J. Harris, and K. Dinsdale, in Proc. of ICAA-4, GIT, Atlanta, GA, USA, 1994, p. 460.

7 V.G. Davydov, L.B. Ber, V.N. Ananiev, A.I. Orozov and M.V. Samarina, in: T. Sato, S. Kumai, T. Kobayashi and Y. Murakami (Eds.) Proc. of ICAA-6, Toyohashi, Japan, 1998, p. 985

8 B. Noble, S.J. Harris, and K. Dinsdale, Acta. Mater. 45 (1997) 2069.

9 H.J. Price, US patent 5879481 (1999).

10 A.J. Hobson, MPhil Thesis, University of Southampton, 1999.

11 M.J. Starink and P.J. Gregson, Mater. Sci. Eng. A211 (1996) 54.

12 M.J. Starink, A.J. Hobson and P.J. Gregson, Scripta Metall. Mater. 34 (1996) 1711.

13 M.J. Starink, P. Wang, I. Sinclair and P.J Gregson, Acta Mater. 47 (1999) 3841.

14 Z.G. Chai, Y. Xu and F.L. Meng, Mater. Charact. 42 (1999) 27.

15 M.J. Starink and P.J. Gregson, Scripta Metall. Mater. 33 (1995) 893.

16 P.D. Pitcher, R.J. Stewart, and S. Gupta, Scripta Metall. 26 (1992) 511.

17 P. Gomiero, F. Livet and O. Lyon, in: M. Peters and P.J. Winkler (Eds.), Proc. Al-Li alloys VI, DGM Metallurgy Information New York, USA, 1992, p. 69 
18 P. Gomiero, Y. Brechet, F. Louchet, A. Tourabi and B. Wack, Acta Metall. Mater. 40 (1992) 857.

19 M.J. Starink and P.J. Gregson, Mater. Sci. Forum 217-222 (1996) 673.

20 M.J. Starink, P. Wang, I. Sinclair and P.J Gregson, Acta Mater. 47 (1999) 3855.

21 J.W. Hutchinson, Proc. R.. Soc. London A319 (1970) 247.

22 J. Lendvai and H.-J. Gudladt, Z. Metallkd. 84 (1993) 242.

23 S.F. Baumann and D.B. Williams, in: T.H. Sanders and E.A. Starke (Eds.), Proc. Al-Li Alloys II, AIME, Warrendale, Pennsylvania, 1984, p. 17

24 B. Noble and S.E. Bray, Acta Mater. 46 (1998) 6163.

25 K. Dinsdale, S.J. Harris and B. Noble, in: T.H. Sanders and E.A. Starke (Eds.), Proc. Al-Li Alloys, AIME, New York, 1981, p. 101

26 T. Sato and A. Kamio, in: T.H. Sanders and E.A. Starke (Eds.), Proc. Al-Li Alloys IV, Atlanta, Georgia, USA, 1994, p. 1

27 S. Ceresara, G. Cocco, F. Fagherazzi and L. Schiffini, Phil. Mag. 35 (1977) 373.

28 G. Cocco, F. Fagherazzi and L. Schiffini, J. Appl. Crystallogr. 10 (1977) 325.

29 A. Livet and D. Bloch, Scripta Metall. 19 (1985) 1147

30. F.W. Gayle and J.B. Vandersande, in: C.A. Baker, P.J. Gregson, S.J. Harris and C.J. Peel (Eds.), Proc. Conf. Al-Li alloys III, Inst. of Metals, London, 1986, p. 376.

31 D.B. Williams, in: T.H. Sanders and E.A. Starke (Eds.), Proc. Al-Li Alloys, AIME, New York, 1981, p. 89

32 A.G. Khachaturyan, T.F. Lindsey and J.W. Morris, Metall. Trans. 19A (1988) 249

33 R. Poduri and L.-Q. Chen, Acta Mater. 44 (1996) 4253.

34 C. Sigli and J.M. Sanchez, Acta Metall. 34 (1986) 1021.

35 C.P. Blankenship and E.A. Starke, Metall. Trans 24A (1993) 833.

36 C.P. Blankenship, E. Hornbogen and E.A. Starke, Mater. Sci. Eng. A169 (1993) 33.

37 S.P. Lynch, Mater. Sci. Eng. A136 (1991) 25.

38 D. Palmer, I. Sinclair and P.J. Gregson, unpublished research.

39 H.J. Price, personal communication, 1999.

40 E. Nembach and G. Neite, Prog. Mater. Sci. 29 (1985) 177.

41 S.M. Jeon and J.K. Park, Acta Mater. 44 (1996) 1449.

42 B.C. Lee and J.K. Park, Acta Mater. 46 (1998) 4181.

43 A.J. Ardell, Metall. Trans. 16A (1985) 2131.

44 G. Tempus, W. Calles and G. Scharf, Mater. Sci. Techn. 7 (1991) 937.

45 X.H. Zeng, M. Ahmad and O. Engler, Mater. Sci. Techn. 10 (1994) 581.

46 P.J. Gregson, D.S. McDarmaid and E. Hunt, Mater. Sci. Techn. 43 (1988) 713. 
47 M.J. Starink and A.-M. Zahra, Phil. Mag. A77 (1998) 187.

48 M.J. Starink, C.Y. Zahra and A.-M. Zahra, J. Therm. Anal. and Calorim. 51 (1998) 933. 